
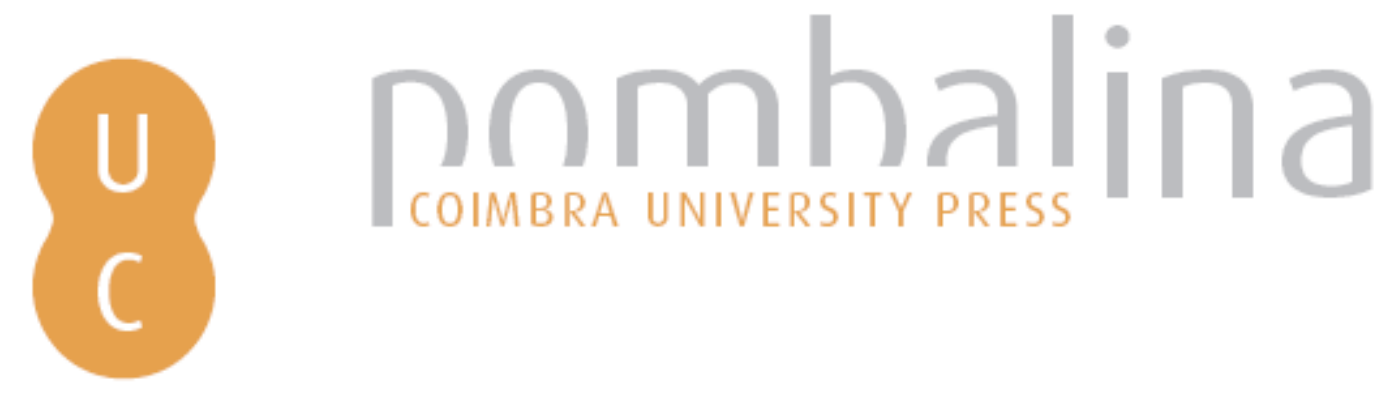

\title{
Produção de micro e nanopartículas utilizando fluidos supercríticos.
}

Autor(es): $\quad$ Bevilaqua, Gabriela; Rosa, Paulo de Tarso Vieira e

Publicado por: Imprensa da Universidade de Coimbra

URL

persistente: $\quad$ URI:http://hdl.handle.net/10316.2/36874

DOI: $\quad$ DOI:http://dx.doi.org/10.14195/978-989-26-0881-5_10

Accessed : $\quad$ 26-Apr-2023 02:27:13

A navegação consulta e descarregamento dos títulos inseridos nas Bibliotecas Digitais UC Digitalis, UC Pombalina e UC Impactum, pressupõem a aceitação plena e sem reservas dos Termos e Condições de Uso destas Bibliotecas Digitais, disponíveis em https://digitalis.uc.pt/pt-pt/termos.

Conforme exposto nos referidos Termos e Condições de Uso, o descarregamento de títulos de acesso restrito requer uma licença válida de autorização devendo o utilizador aceder ao(s) documento(s) a partir de um endereço de IP da instituição detentora da supramencionada licença.

Ao utilizador é apenas permitido o descarregamento para uso pessoal, pelo que o emprego do(s) título(s) descarregado(s) para outro fim, designadamente comercial, carece de autorização do respetivo autor ou editor da obra.

Na medida em que todas as obras da UC Digitalis se encontram protegidas pelo Código do Direito de Autor e Direitos Conexos e demais legislação aplicável, toda a cópia, parcial ou total, deste documento, nos casos em que é legalmente admitida, deverá conter ou fazer-se acompanhar por este aviso.

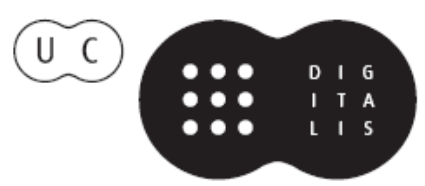


IOMATERIAIS APLICADOS AO DESENVOLVIMENTO DE SISTEMAS TERAPÊUTICOS AVANÇADOS

IOMATERIALES APLICADOS AL DISEÑO DE SISTEMAS TERAPÉUTICOS AVANZADOS

Hermínio C. de Sousa Mara E. M. Braga Alejandro Sosnik (editores) 


\title{
CAPÍTULO 10. PRODUÇÃO DE MICRO E NANOPARTÍCULAS UTILIZANDO FLUIDOS S UP E R C R ÍT I C OS
}

\begin{abstract}
Gabriela Bevilaqua, Paulo de Tarso Vieira e Rosa Departamento de Físico-Química, Instituto de Química, Universidade Estadual de Campinas (UNICAMP). Rua Josué de Castro S/N, 13083-970, Campinas, Brasil.
\end{abstract}

\section{Resumo:}

A formação de partículas com tamanho e morfologia bem definidas apresenta grande interesse nas indústrias farmacêuticas. A redução do tamanho de partículas de compostos bioativos leva a um aumento na taxa de dissolução do fármaco no organismo e por consequência aumenta sua biodisponibilidade, permitindo reduzir a dose de medicamento ingerida, diminuindo efeitos colaterais e minimizando custos. Tecnologias que empregam fluidos supercríticos, geralmente dióxido de carbono, têm sido comumente empregadas para este fim. Diversos métodos foram desenvolvidos para a produção de partículas de compostos hidrofílicos ou hidrofóbicos. Além disto, os princípios ativos podem ser co-precipitados com polímeros para formação de sistemas para liberação controlada do fármaco. Neste capítulo são apresentadas as principais tecnologias supercríticas empregadas na formação de partículas, a rápida expansão de solução supercrítica (RESS) com o fluido supercrítico agindo como solvente, a utilização do antisolvente supercrítico (SAS) para precipitar compostos mais hidrofílicos presentes em soluções de solventes orgânicos e a produção de partículas a partir de soluções gasosas saturadas (PGSS), com o fluido 
supercrítico agindo como soluto, demonstrando as especificidades de cada método e exemplos de aplicações. As influências das variáveis operacionais tais como temperatura, pressão, vazão, concentração de soluções e diâmetro de capilares nos tamanhos e morfologias das partículas também são discutidas.

Palavras-Chave: Formação de partículas; tecnologias supercríticas; expansão rápida de soluções supercríticas; antisolvente supercrítico; solução gasosa saturada.

\section{Abstract:}

The production of particles with well-defined size and morphology is of large interest in pharmaceutical industries. The bioactive compound particle size reduction leads to an increase of its dissolution rate in the organism, increasing its bioavailability, allowing the administration of lower dosages, decreasing side effects, and decreasing treatment costs. Supercritical fluid technologies, mainly using carbon dioxide, are used to produce such particles. Several methods were developed to produce particles of hydrophilic or hydrophobic compounds. Furthermore, the active molecules can be co-precipitated with polymer in order to produce controlled release systems. In this chapter the main supercritical technologies to produce particles (the rapid expansion of supercritical solution (RESS) with the supercritical fluid acting as a solvent, the anti-solvent supercritical (SAS) to precipitate more polar drugs from organic solvent solutions, and particles from gas saturated solution (PGSS) with the supercritical fluid being used as a solute) are presented, showing the methods specificities and some applications. The influence of operational variables such as temperature, pressure, flow rate, concentrations, and capillary diameters in the particle size and morphology are discussed.

Keywords: Particle formation; supercritical technologies; rapid expansion of supercritical solution; supercritical antisolvent; gas saturated solution. 


\subsection{Introdução}

Embora a formação de partículas com tamanho e morfologia bem definidas seja uma demanda de vários setores de pesquisa e produção (catalisadores, explosivos, adsorventes, etc.), é na área farmacêutica que esta necessidade se torna mais evidente. A redução do tamanho de partículas de compostos bioativos é importante para aumentar a taxa de dissolução do fármaco no organismo uma vez que partículas menores apresentam maior biodisponibilidade. Deste modo, é possível reduzir a dose de medicamentos ingerida, diminuindo efeitos colaterais e minimizando custos. Além disso, por meio do ajuste de tamanho de partículas farmacológicas, é possível promover a liberação controlada de princípios ativos, aumentando o tempo de circulação da droga no organismo do paciente. Além de tamanhos pequenos, é desejável que partículas apresentem a menor distribuição de tamanho possível, uma vez que partículas com características diferentes podem apresentar ações farmacológicas distintas [1].

As técnicas convencionais de formação de partículas, tais como spray-drying e evaporação da emulsão/solvente, apresentam algumas desvantagens, como o uso de altas temperaturas, que podem promover a degradação térmica do material a ser micronizado. Além disso, estas técnicas podem gerar partículas com grande distribuição de tamanho, o que não é conveniente para fármacos. Outras técnicas convencionais, como liofilização, extrusão e granulação, não permitem o controle adequado do tamanho das partículas formadas, além de necessitar de processos com várias etapas [2].

Nesse contexto, o uso de tecnologias supercríticas tem se mostrado interessante na formação de partículas orgânicas. Nestas tecnologias, um fluido em condições supercríticas é utilizado como solvente, anti-solvente ou soluto e as características do fluido podem ser alteradas facilmente com variações na pressão e temperatura do sistema $[1,3]$.

Uma das vantagens destas tecnologias é a versatilidade das condições operacionais de processo, o que torna possível alterar com facilidade as condições de solvência do fluido empregado [3]. As tecnologias su- 
percríticas permitem controlar características das partículas formadas, dando origem a drogas com maior funcionalidade farmacêutica. Desta forma, é possível sintetizar partículas de menor tamanho, com distribuição de tamanho homogênea e com morfologia específica, de modo a aumentar a biodisponibilidade do fármaco no organismo [4]. Além disso, as partículas formadas em meio supercrítico apresentam, de modo geral, menor quantidade de solvente residual que as partículas formadas pelos métodos tradicionais [5].

O fluido comumente utilizado na produção de partículas é o dióxido de carbono supercrítico $\left(\mathrm{CO}_{2}\right)$, que apresenta as vantagens de apresentar baixa toxicidade, ter baixo custo, ser inerte nas condições empregadas e não ser poluente. Além disso, seu ponto crítico permite a formação de partículas em condições operacionais amenas, o que é desejável para compostos termolábeis [1]. Por apresentar alto coeficiente de difusão [5], pode se difundir em cadeias poliméricas e atuar como agente plastificante, tornando possível a composição de partículas de drogas em polímeros biocompatíveis [6].

Há várias técnicas para a produção de partículas utilizando tecnologias supercríticas, tais como a Expansão Rápida de Soluções Supercríticas (RESS), o Anti-solvente Gasoso (GAS), o Anti-Solvente Supercrítico (SAS) e o Aumento da Dispersão da Solução por Fluido Supercrítico (SEDS) e a Precipitação a partir de Soluções Gasosas Saturadas (PGSS) [1].

A aplicação destas técnicas depende das características da droga utilizada. Desta forma, o $\mathrm{CO}_{2}$ pode exercer diferentes funções, dependendo da solubilidade do fármaco no meio supercrítico. Para drogas solúveis no meio supercrítico, utiliza-se a técnica RESS. Para fármacos que apresentam pequena solubilidade no meio supercrítico, utilizam-se técnicas onde o fluido atua como anti-solvente. Deste grupo, a técnica mais difundida é a SAS, discutida na Seção 10-2.2. Por último, a técnica PGSS será abordada, uma vez que representa um processo onde o fluido supercrítico não atua como solvente nem como anti-solvente e sim como um soluto capaz de permitir o escoamento do material que irá ser utilizado para a formação da partícula. 


\subsection{Técnicas para produção de partículas}

\subsubsection{Rápida Expansão da Solução Supercrítica (RESS)}

A técnica RESS baseia-se na solubilização do soluto na fase supercrítica e posterior expansão da mistura. Deste modo, é necessário que a droga a ser utilizada seja solúvel no meio supercrítico. Devido a despressurização do sistema, ocorre uma diminuição da densidade do meio e consequente supersaturação do soluto de interesse, que promove a rápida nucleação e formação de partículas com pequena distribuição de tamanho [1, 3, 7, 8]. Esta técnica tem sido apontada com grande potencial para combinar a produção de partículas de menor tamanho e produção de microesferas biopoliméricas carregadas, sendo interessante para transporte de drogas. Além disso, por meio da RESS, pode-se co-precipitar polímeros com ingredientes ativos, a fim de melhorar o processo de liberação de fármacos [3].

Uma das vantagens da técnica RESS é a possibilidade de obtenção de partículas submicrométricas com diâmetros menores que $500 \mathrm{~nm}$ [9], de modo a atender uma demanda significativa da indústria farmacêutica. É possível também, por meio desta técnica, obter partículas com pequena distribuição de tamanho, de modo a evitar efeitos indesejáveis em fármacos, como imprevisibilidade de ação farmacocinética e diferentes perfis de liberação [1]. O tamanho médio e sua distribuição serão funções das condições experimentais utilizadas no processo de produção das partículas. Um esquema de unidade de produção de partículas por RESS pode ser observada na Figura 10.1. 


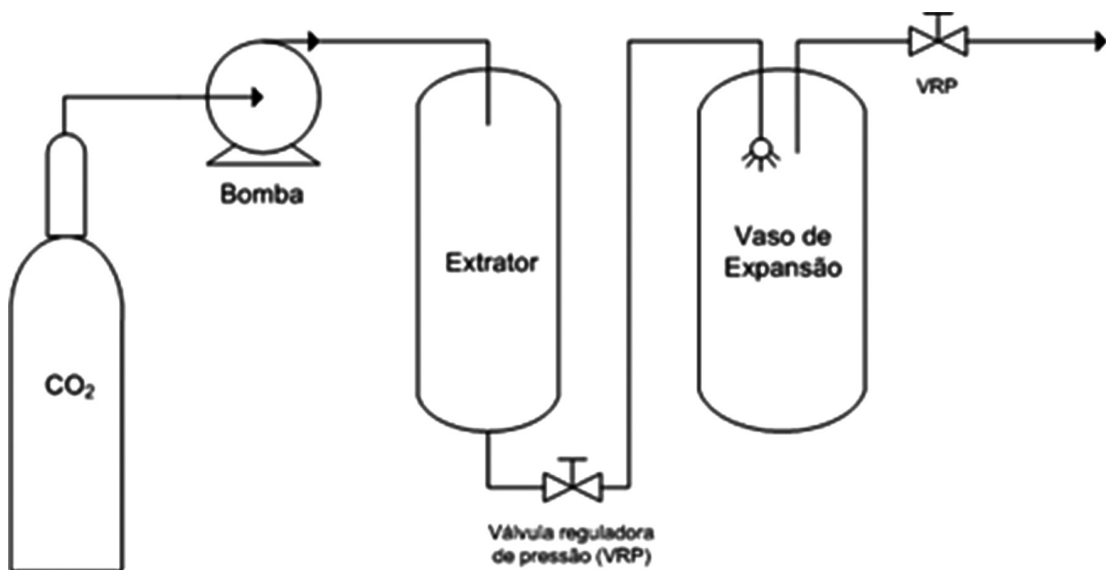

Figura 10.1. Representação esquemática do sistema de formação de partículas pela técnica RESS.

Vários parâmetros podem influenciar o tamanho das partículas formadas pela técnica RESS. As condições operacionais de utilizada para micronizar substâncias bioativas pela técnica RESS são mostradas na Tabela 10.1.

Tabela 10.1. Micronização de substâncias bioativas utilizando a técnica RESS. ${ }^{1}$ condição da extração; 2 condição da pré-expansão.

\begin{tabular}{llllllll}
\hline Substrato & $\begin{array}{l}\text { Pressão } \\
(\mathbf{b a r})\end{array}$ & $\begin{array}{l}\text { Temp } \\
(\mathbf{K})\end{array}$ & $\begin{array}{l}\text { Diâmetro } \\
\text { do } \\
\text { orifício } \\
(\mathbf{m m})\end{array}$ & $\begin{array}{l}\text { Tamanho } \\
(\boldsymbol{\mu m})\end{array}$ & $\begin{array}{l}\text { Dist. } \\
\text { Spray } \\
(\mathbf{c m})\end{array}$ & $\begin{array}{l}\text { Co- } \\
\text {-solvente }\end{array}$ & $\begin{array}{l}\text { Refe- } \\
\text { rência }\end{array}$ \\
\hline colesterol & $100-160^{1}$ & $313-333^{1}$ & $0,15-0,24$ & $0,62-4,83$ & - & - & 10 \\
raloxifeno & $100-180^{1}$ & $313-353^{1}$ & 0,03 & $0,018-0,136$ & $5-10$ & - & 11 \\
linestrenol & $150-300_{2}$ & $318-333_{2}$ & 0,6 & $<0,2$ & - & mentol & 9 \\
nabumetona & $150-200^{1}$ & $308-328^{1}$ & 0,25 e 0,5 & $6,9-19,7$ & 2,5 e 7,0 & - & 12 \\
creatina & $140-220^{1}$ & $313-333^{1}$ & $0,45-1,7$ & $0,36-9,06$ & $1-7$ & - & 13 \\
digitoxina & $100^{1}$ & $363-383_{2}$ & 0,05 & $0,068-0,458$ & $3-7$ & etanol & 15 \\
diclofenaco & $140-220^{1}$ & $313-333^{1}$ & $0,45-1,7$ & $1,33-10,92$ & $1-10$ & - & 16 \\
naproxeno & $200-300_{2}$ & $323-363_{2}$ & 0,05 & $0,56-0,82$ & - & - & 8 \\
\hline
\end{tabular}




\subsubsection{Tamanho das partículas}

\subsection{Temperatura}

Nos experimentos utilizando a técnica, verificou-se que o aumento da temperatura de extração resulta em um aumento no tamanho da partícula para experimentos com pressão na faixa de 200 a 230 bar, sendo que este efeito foi menor em pressões mais altas. A mesma tendência é observada com a variação de temperatura de pré-expansão, definida como a temperatura da mistura da droga e fluido supercrítico antes de passar pelo orifício de expansão. No entanto, Satvati e Lotfollahi [10] obtiveram partículas de colesterol por meio da técnica RESS e o aumento da temperatura promoveu uma diminuição do tamanho das partículas, contrariando a tendência inicial observada em outros trabalhos. Os autores sugerem que há dois fenômenos competitivos que explicam este fato. O primeiro é que o aumento da temperatura causa a diminuição do poder solvente do fluido supercrítico, diminuindo a concentração de colesterol neste fluido logo na entrada da câmara de extração, diminuindo a taxa de nucleação no vaso de expansão. Por outro lado, a diminuição da concentração de colesterol na fase supercrítica também diminui a taxa de crescimento das partículas. Desta forma, o segundo efeito seria o predominante, levando a menores partículas.

$\mathrm{Na}$ produção de partículas nanométricas de raloxifeno, o aumento da temperatura de 313 para $333 \mathrm{~K}$ foi responsável pela diminuição do tamanho das partículas. O contrário foi observado em temperaturas mais altas, de modo que o incremento da temperatura de 333 para $353 \mathrm{~K}$ foi responsável pela produção de partículas maiores, com aumento do diâmetro médio de 18,9 para $23,0 \mathrm{~nm}$. No entanto, esta variação foi estatisticamente pouco significativa [11]. Partículas de linestrenol também sofreram influência negativa da temperatura, sendo que partículas produzidas a $318 \mathrm{~K}$ apresentaram maior tamanho que as partículas produzidas a $333 \mathrm{~K}$ [9].

De modo geral, o aumento da temperatura provoca uma diminuição da densidade do fluido supercrítico, diminuindo também sua capacidade 
de solvência. Por outro lado, o aumento da temperatura promove um aumento da pressão de vapor do soluto, de modo a aumentar a solubilidade da droga no meio supercrítico. Existe assim um valor de pressão abaixo do qual o primeiro efeito é o mais importante e há uma diminuição da solubilidade do composto com o aumento da temperatura. Acima deste valor de pressão, conhecida como pressão de cruzamento, ocorre o efeito contrário. Este valor da pressão é uma característica de cada composto e, portanto, fica complexa a compreensão do efeito da temperatura para todos os sistemas. A não concordância do efeito da temperatura no tamanho da partícula pode também ter ocorrido por diferenças em outros parâmetros, tais como diâmetro de orifício do capilar, pressão ou distância do spray. A influência da temperatura de pós-expansão, ou seja, na câmara de expansão, no tamanho de partículas de nabumetona também foi analisada, mostrando que o aumento deste parâmetro foi responsável pela produção de partículas de maior tamanho. O mesmo estudo, no entanto, mostra que a temperatura de pré-expansão não influencia significativamente o tamanho da partícula [12].

\subsection{Pressão}

O aumento da pressão de extração no sistema tende a gerar partículas de menor tamanho, uma vez que aumenta a densidade do fluido supercrítico, aumentando sua capacidade de solvência. Deste modo, maior quantidade de droga será solubilizada na fase supercrítica, estimulando as etapas de supersaturação e nucleação. A formação de partículas menores foi mais evidente em faixas de maior valor de pressão de extração. O efeito da pressão no tamanho de colesterol micronizado foi considerado desprezível na faixa de 100 a 130 bar. No entanto, quando se eleva a pressão à 160 bar, o tamanho médio de partícula passa de 2,25 para 1,91 um [10]. O aumento da pressão de pré-expansão, por sua vez, mostrou efeito positivo no tamanho, de modo que maiores partículas de linestrenol foram produzidas em maior valor de pressão. Partículas formadas à pressão de pré-expansão igual a 150 bar apresentaram 
tamanho máximo de 172,6 nm. Já à pressão de 300 bar, as partículas atingiram tamanho de 325,6 nm [9]. A temperatura de extração em geral não apresenta uma grande amplitude, ficando em todos os experimentos na faixa de 313 e $333 \mathrm{~K}$.

\subsection{Diâmetro de orifício do capilar}

O diâmetro de orifício do capilar também mostrou influenciar o tamanho das partículas, sendo que partículas com menor tamanho médio foram produzidas em sistemas cujo diâmetro de orifício era menor. Esse efeito pode ser explicado pelo fato de que a supersaturação na câmara de expansão aumenta, assim como a taxa de nucleação, com a diminuição do diâmetro do capilar, de modo a produzir partículas menores devido à maior concentração da substância bioativa no fluido supercrítico. Hezave et al. [13] produziram partículas de creatina monoidratada e o aumento do diâmetro de 450 para $1.700 \mu \mathrm{m}$ foi responsável pelo aumento do tamanho médio das partículas de 0,36 para $5,69 \mu \mathrm{m}$. O mesmo efeito foi observado por Su et al. [12] ao aumentar o diâmetro do orifício de 25 para $50 \mu \mathrm{m}$. Nestas condições, o tamanho das partículas de nabumetona aumentaram de 4,2 para 19,4 $\mu \mathrm{m}$. No entanto, na micronização de colesterol percebeu-se o efeito contrário do observado. O aumento do diâmetro do capilar de 150 para $240 \mu \mathrm{m}$ promoveu a redução do tamanho médio das partículas de colesterol micronizadas (de 2,54 para 1,53 $\mu \mathrm{m}$ ) [10]. Segundo os autores, a velocidade de passagem aumenta com a diminuição do diâmetro do capilar. Desta forma, o tempo de residência das partículas durante o processo de expansão diminui, minimizando o fenômeno de crescimento das partículas. Além disso, quando o diâmetro aumenta, a probabilidade de colisão das partículas diminui, evitando sua aglomeração. No entanto, Hezave et al. [13] atribui o aumento do tamanho médio da partícula ao fato de que a diminuição do diâmetro promove o aumento da supersaturação e, consequentemente, das taxas de nucleação, estimulando a produção de partículas menores. Esta diferença no tamanho das 
partículas pode ser devido à diferença de solubilidade das drogas na fase fluida. Nabumetona apresenta solubilidade cerca de 40 vezes maior que a solubilidade do colesterol em $\mathrm{CO}_{2}$ supercrítico nas condições experimentais da região estudada [12, 14]. O aumento do diâmetro do orifício no experimento com a droga menos solúvel (colesterol) talvez não tenha sido suficientemente grande para reduzir drasticamente a taxa de nucleação das partículas, uma vez que solubilidade do colesterol é menor que a solubilidade da nabumetona. Consequentemente, há produção de partículas de colesterol de menor tamanho. O efeito do aumento do diâmetro de orifício no tempo de residência pode ter sido determinante para a droga mais solúvel, promovendo a aglomeração das partículas de nabumetona.

\subsection{Distância do spray}

A distância do spray em relação ao sistema de coleta das partículas também é um parâmetro que interfere no tamanho das partículas produzidas pela técnica RESS e seu efeito também é regido por fenômenos concorrentes. Se a distância for grande o suficiente, as partículas podem se romper durante a expansão, de modo que seu tamanho tende a diminuir. Partículas de raloxifeno sofreram diminuição do seu tamanho médio (de 33,7 para 18,9 nm) com o aumento da distância de spray de 7 para $10 \mathrm{~cm} \mathrm{[11].} \mathrm{O} \mathrm{mesmo} \mathrm{foi} \mathrm{observado} \mathrm{por} \mathrm{Atila} \mathrm{et} \mathrm{al.} \mathrm{[15]} \mathrm{ao} \mathrm{aumentar}$ a distância de spray de 3 para $7 \mathrm{~cm}$ na micronização de partículas de digitoxina. O outro efeito possível, contrário a este primeiro, é a aglomeração das partículas de droga causada pela diminuição da distância do spray, que pode ser explicado pela diminuição do ângulo entre as partículas, favorecendo a aglomeração. Partículas de diclofenaco sofreram aumento do seu tamanho médio (de 3,64 para 5,99 $\mu \mathrm{m}$ ) com o aumento da distância de spray de 1 para $10 \mathrm{~cm} \mathrm{[16].} \mathrm{A} \mathrm{variação,} \mathrm{no} \mathrm{entanto,} \mathrm{da}$ distância de spray na micronização de nabumetona e creatina não afetou significativamente o tamanho médio das partículas, como mostrado por Su et al. [12] e Hezave et al. [13], respectivamente. 


\subsubsection{Morfologia}

A morfologia das partículas também é afetada pelas condições operacionais do processo. Uma vez que polimorfos podem alterar propriedades físico-químicas e diminuir a estabilidade de drogas sólidas, sua presença é indesejável em formulações farmacêuticas. Além disso, diferentes formas cristalinas de partículas de fármacos podem apresentar diferentes ações terapêuticas e biodisponibilidade, além de interferirem na liberação da droga no organismo [1, 13]. As análises por difração de raio-X mostraram que existe uma grande tendência de a técnica RESS diminuir a cristalinidade do material $[8,10,11,13,16,17]$. As partículas originais apresentam diversas morfologias, podendo apresentar características retangulares, alongadas ou até mesmo morfologia irregular. As partículas processadas, por sua vez, passaram a apresentar morfologia próxima do formato esférico [13, 16] e irregular [17]. No entanto, ao analisar, utilizando cromatografia líquida associada à espectrometria de massas, digitoxina processada pela técnica RESS, os autores [15] não observaram alterações na estrutura da droga. Vemavarapu et al. [18], ao estudar a dopagem de matrizes com substâncias bioativas utilizando a técnica RESS, observaram que a presença de aditivos pode alterar a cinética de nucleação dos compostos, assim como interferir no crescimento de cristais e que a redução da cristalinidade das matrizes, por outro lado, auxiliou a coprecipitação. Satvati e Lotfollahi [10] observaram poucas diferenças no formato das partículas originais e processadas. Entretanto, dependendo das condições operacionais, foram produzidas partículas com morfologia semi-esférica, com uma tendência à formação de partículas aglomeradas.

Nos testes in vitro realizados foi observado um aumento da taxa de dissolução das drogas processadas por RESS quando comparada com a taxa de dissolução de fármacos não processados. Uma vez que a taxa de dissolução está relacionada com a biodisponibilidade do fármaco no organismo, seu incremento representa um efeito positivo na produção de partículas de substâncias bioativas, desde que se possa prolongar a ação farmacológica das mesmas. Partículas de naproxeno apresentaram tamanho vinte e duas vezes menor que as partículas do fármaco não processado. A taxa de dissolução, 
como consequência da diminuição do tamanho, é maior no fármaco processado. No entanto, as partículas processadas também apresentaram diminuição do seu grau de cristalinidade. Partículas de naproxeno foram estabilizadas por meio desta técnica (temperatura de extração igual a 313 K, pressão de extração igual à pressão de pré-expansão de 200 bar e temperatura de pré-expansão igual a $343 \mathrm{~K}$ ). Partículas com diâmetro de 0,3 $\mu \mathrm{m}$ foram estabilizadas em solução aquosa de polímeros [8].

Além do processo de micronização, que tem como objetivo diminuir o tamanho das partículas e as tornarem mais biodisponíveis, é possível, por meio da técnica RESS, a formação de sistemas de liberação de substâncias bioativas, tais como lipossomas. Lipossomas são vesículas compostas de uma ou mais camadas lipídicas concêntricas contendo um núcleo aquoso. As camadas são formadas por fosfolipídios que, na presença de água, se arranjam de modo a minimizar interações não favoráveis. Lipossomas têm sido utilizados com bastante frequência em sistemas controlados de liberação de drogas. Com isso, minimiza-se problemas como a degradação de compostos bioativos e uso de doses elevadas de drogas, entre outros [19]. As técnicas tradicionais de formação de lipossomas (evaporação de fase reversa, formação de emulsão, etc.), de modo geral, apresentam baixa eficiência de encapsulamento. Nesse contexto, as tecnologias que utilizam $\mathrm{CO}_{2}$ supercrítico apresentam vantagens na formação de compostos encapsulados, uma vez que o uso do dióxido de carbono promove uma diminuição da temperatura de transição de fase do surfactante fosfolipídico (gel-fluido), maior controle das características dos lipossomas, tais como tamanho e estabilidade dos mesmos [20]. Os parâmetros do processo, tais como temperatura e pressão, também exercem influência nas características das partículas formadas, como eficiência de encapsulamento e carga da droga.

O óleo essencial extraído do rizoma Atractylodes macrocephala Koidz, fármaco utilizado na terapia de doenças digestivas e tumores, foi encapsulado em fosfatidilcolina por meio da técnica RESS modificada, utilizando etanol como cossolvente. Foi utilizado colesterol a fim de aumentar a estabilidade do lipossoma formado. O óleo essencial é formado por componentes lipofílicos que apresentam baixa solubilidade em água. Foi observado baixos valores de carga de droga no lipossoma em valores 
mais baixos de pressão, possivelmente devido à redução da habilidade de empacotamento das bicamadas fosfolipídicas. Já a influência dos valores de temperatura do fluido supercrítico foi analisada na faixa de 313 a $343 \mathrm{~K}$. O aumento da temperatura apresentou maior eficiência de encapsulamento até um valor máximo de temperatura (338 K), com posterior queda da eficiência de encapsulamento. O cossolvente (etanol) utilizado na técnica aumenta a interação entre as moléculas do material lipossômico e a fase supercrítica. Houve melhor eficiência de encapsulamento utilizando teores de cossolvente na faixa de 5 a 15\% (fração molar de etanol em $\mathrm{CO}_{2}$ ), com pressão de 300 bar e temperatura de 338 K. Os autores afirmam que a membrana fosfolipídica é destruída em quantidades de etanol acima de $15 \%$. As condições operacionais ótimas obtidas foram pressão de 300 bar, temperatura de $338 \mathrm{~K}$ e fração molar de etanol de 15\%. A técnica permitiu a obtenção de partículas com pequena distribuição de tamanho e a taxa de dissolução dos óleos essenciais presentes no rizoma aumenta consideravelmente quando incorporado nos lipossomas [21].

Existem algumas variações do processo de expansão rápida de solução supercrítica. Enquanto na técnica RESS a expansão ocorre em uma câmara vazia, na técnica RESSA (Rápida Expansão da Solução Supercrítica em Solução Aquosa) a expansão da solução ocorre na presença de água. A técnica RESOLV (Rápida Expansão da Solução Supercrítica no Solvente Líquido) é também uma variação da técnica RESS, onde o vaso de expansão é preenchido por uma solução líquida. Partículas menores tendem a ser formadas por esta técnica, uma vez que a expansão em meio líquido, tende a inibir fenômenos de coalescência e, consequentemente, a produção de partículas com menores diâmetros [22].

\subsubsection{Anti-Solvente Supercrítico (SAS)}

Nem sempre é possível dissolver a droga de interesse na fase supercrítica. Assim, as substâncias bioativas são dissolvidas em um solvente orgânico solúvel no fluido supercrítico, que atua como anti-solvente. A solução orgânica e o $\mathrm{CO}_{2}$ supercrítico são injetados em uma câmara 
pressurizada de precipitação na qual ocorre a remoção do solvente solvente orgânico pelo $\mathrm{CO}_{2}$, promovendo a precipitação da droga. A transferência de massa entre a fase supercrítica e o solvente orgânico faz com que ocorra a supersaturação da droga no meio, de modo a precipitá-la com a expansão da mistura. A técnica SAS tem se mostrado eficiente na micronização de vários tipos de partículas, tais como polímeros e biopolímeros, supercondutores, explosivos, entre outros compostos [1].

Os fatores que afetam o tamanho das partículas obtidas e sua morfologia são temperatura, pressão, concentração e vazão da solução droga, relação entre as vazões da solução orgânica e do fluido supercrítico, entre outros. O tamanho das partículas obtidas por SAS são, em geral, menores que as obtidas pela técnica RESS. Um dos fatores que pode explicar esta tendência é que a atomização na técnica SAS é muito eficiente devido à baixa tensão interfacial entre a solução orgânica e o fluido utilizado como anti-solvente [23]. Essa rápida transferência de massa entre solvente e anti-solvente faz com que ocorra diminuição do poder de solvência do solvente orgânico, promovendo a supersaturação e gerando partículas pequenas e com pequena distribuição de tamanho [24].

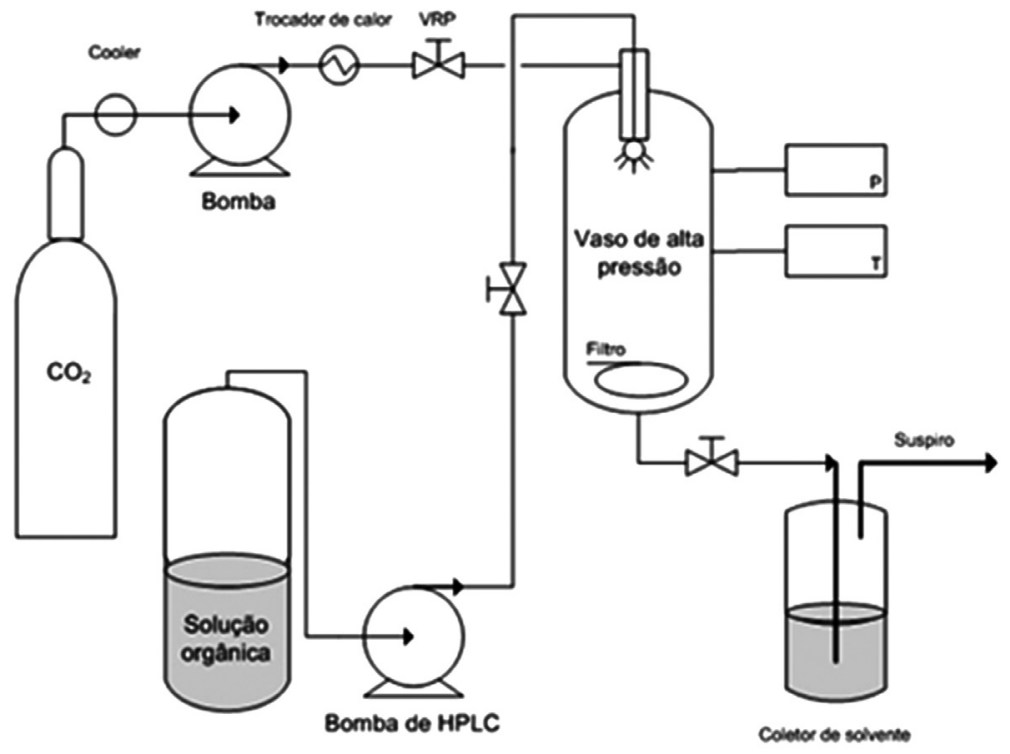

Figura 10.2. Representação esquemática do sistema de formação de partículas pela técnica (SAS). 
A representação esquemática de um processo de produção de partículas usando o fluido supercrítico como um anti-solvente pode ser visualizada na Figura 10.2. Neste processo, a solução orgânica forma um jato na entrada da câmara de precipitação. Este jato, devido aos processos de transferência de massa e de instabilidade mecânica causada pelo escoamento a altas velocidades que a solução orgânica desenvolve no capilar, tende a se romper favorecendo à formação de partículas pequenas. Vazões muito baixas da solução orgânica devem ser evitadas para não favorecer a difusão do $\mathrm{CO}_{2}$ supercrítico pelo capilar com a precipitação do material na linha. Esta precipitação pode acarretar no entupimento do capilar com a interrupção do processo. O filtro presente na parte inferior da coluna deve ter abertura de poro tal que consiga reter as menores partículas formadas durante o processo. Da mesma forma que na RESS, a bomba de $\mathrm{CO}_{2}$ deve ser refrigerada para garantir que o fluido esteja líquido neste ponto. Devido ao mesmo fato, o cilindro de $\mathrm{CO}_{2}$ deve ter tubos pescadores para coletar a fase líquida presente na parte inferior do reservatório. A Tabela 10.2 apresenta alguns exemplos de partículas produzidas por tecnologina supercrítica utilizando o método SAS.

Tabela 10.2. Produção de substâncias bioativas utilizando a técnica SAS

\begin{tabular}{|c|c|c|c|c|c|c|c|}
\hline Substrato & $\begin{array}{l}\text { Pressão } \\
\text { (bar) }\end{array}$ & $\begin{array}{l}\text { Temp. } \\
\text { (K) }\end{array}$ & Solvente & $\begin{array}{c}\text { Conc. de } \\
\text { soluto } \\
(\mathbf{m g} . \\
\left.\mathbf{m L}^{-1}\right)\end{array}$ & $\begin{array}{c}\text { Vazão } \\
\text { solução } \\
(\mathbf{m L} . \\
\left.\text { min }^{-1}\right)\end{array}$ & $\begin{array}{l}\text { Tamanho } \\
(\mu \mathrm{m})\end{array}$ & Ref. \\
\hline acetato de gadolínio & $90-200$ & $308-363$ & DMSO & $20-30$ & - & $0,23-0,56$ & 25 \\
\hline $\begin{array}{l}\text { extrato de Ginkgo } \\
\text { biloba }\end{array}$ & $100-400$ & $308-363$ & etanol & $1,25-5$ & $3,0-12,0$ & $<0,16$ & 26 \\
\hline vitexina & $150-300$ & $313-343$ & DMSO & $1-2,5$ & $3,3-8,4$ & $\begin{array}{c}0,138- \\
-0,9616\end{array}$ & 27 \\
\hline aztreonam & $\begin{array}{l}308,2- \\
-318,2\end{array}$ & $70-250$ & DMSO & 10 & $\begin{array}{l}30 \\
\text { g.min }\end{array}$ & $0,109-1,454$ & 28 \\
\hline camptotecina & $100-250$ & $308-341$ & DMSO & $1,25-5$ & $3,3-13,2$ & $0,38-0,93$ & 29 \\
\hline sulfatiazol & $100-200$ & $313-343$ & acetona & $5-18$ & - & $\begin{array}{c}0,78-16,57 \\
\text { (esferas) }\end{array}$ & 30 \\
\hline calceína (lipossoma) & 308 & $90-130$ & etanol & $150-250$ & 0,38 & $0,1-500$ & 38 \\
\hline axetil cefuroxima/PVP & $70-200$ & $308-323$ & metanol & $50-150$ & - & $1,88-3,97$ & 2 \\
\hline cetirizina/ $\beta-C D$ & 150 & 308,15 & DMSO & - & $\begin{array}{c}0,91 \\
\text { g. } \mathrm{min}^{-1}\end{array}$ & $<4,16$ & 35 \\
\hline
\end{tabular}




\subsubsection{Tamanho das partículas}

\subsection{Pressão}

Os estudos que analisam a influência da pressão como variável do processo mostram que o aumento deste parâmetro causa, quase sempre, uma diminuição do tamanho médio das partículas e da sua distribuição de tamanho. Isso pode ser explicado pelo aumento da densidade do anti-solvente, $\mathrm{CO}_{2}$, que promove rápida transferência de massa e maiores taxas de supersaturação, gerando partículas de tamanho reduzido [2]. De Marco e Reverchon [25] observaram a diminuição do diâmetro médio de partícula de acetato de gadolínio dissolvido em dimetilsulfóxido (DMSO) com o aumento da pressão. Partículas de tamanho micro foram obtidas até 180 bar, com obtenção de partículas submicrométricas em maiores valores de pressão. A mesma tendência foi observada na produção de partículas de extrato de Ginkgo biloba utilizando etanol como solvente. A variação da pressão de 100 a 400 bar promoveu uma redução do tamanho da partícula. No entanto, foi observado que a influência da pressão se apresenta significativa apenas até 200 bar, com a obtenção de partículas de tamanho médio de 81,2 nm [26]. Em valores mais altos de pressão, o diâmetro médio sofre pouca alteração com o incremento da pressão. Isso pode ser explicado pelo fato de que fenômenos competitivos ocorrem nas diferentes condições do processo. Embora o aumento da pressão seja responsável pelo aumento da densidade da fase fluida, promovendo maior supersaturação do meio, o incremento da pressão diminui a difusividade do solvente orgânico no fluido, diminuindo a taxa de transferência de massa e produzindo partículas de tamanho maiores, anulando o efeito da pressão na redução do tamanho das partículas [2]. Os resultados mostrados por $\mathrm{Zu}$ et al. [27] na produção de partículas vitexina utilizando DMSO como solvente de corroboram esta ideia, uma vez que houve diminuição do tamanho das partículas quando a pressão foi aumentada de 150 a 250 bar, com ligeiro aumento do diâmetro médio das partículas com a variação de pressão de 250 a 300 bar. Nas condições operacionais ótimas, com pressão igual a 250 
bar, foram obtidas partículas nanométricas com tamanho médio de $126 \pm 18$ $\mathrm{nm}$. A mesma tendência foi verificada na produção de partículas aztreonam com DMSO como solvente obtidas pela técnica SAS, sendo que as menores partículas foram produzidas em maiores valores de pressão. No entanto, é importante observar que, embora a faixa de pressão estudada seja relativamente extensa (de 70 a 250 bar), o rápido decréscimo no tamanho da partícula ocorreu no estreito intervalo de pressão entre 80 e 85 bar, com produção da droga micronizada com tamanho médio na faixa entre 109 e $154 \mathrm{~nm}$. Acima de 85 bar a influência deste parâmetro não se mostrou significativa no tamanho das partículas [28]. A inflexão da influência da pressão também foi observada na micronização de camptotecina utilizando DMSO como solvente. Desta forma, de 100 a 200 bar, o aumento da pressão causou diminuição do tamanho das partículas. Na faixa de 200 a 250 bar, foi observado o efeito contrário. No valor de pressão considerado ótimo, $200 \mathrm{bar}$, foram produzidas partículas de 0,25 $\pm 0,02 \mu \mathrm{m}$ [29].

Se na maioria dos estudos foi observada a diminuição do tamanho da partícula com o aumento da pressão, com redução desta influência em maiores valores de pressão, alguns autores registraram o aumento do tamanho da partícula com o incremento da pressão.

Partículas de sulfatiazol foram micronizadas utilizando acetona como solvente. A faixa de pressão estudada foi de 100 a 200 bar, sendo que o aumento da pressão aumenta o tamanho da partícula. Os autores acreditam que o aumento da pressão causa um aumento da solubilidade da droga, de modo a aumentar o gradiente de concentração entre a fase liquida dispersa e a fase leve contínua, diminuindo a rapidez dos fenômenos de transferência de massa. Deste modo, o tamanho médio das partículas aumenta, assim como sua distribuição de tamanho. No entanto, houve discrepâncias nas concentrações de soluto dissolvido no solvente orgânico, o que pode explicar a comportamento diferente do tamanho das partículas em diferentes valores de pressão. Outro fato a ser observado é o solvente empregado. Uma vez que o aumento da pressão diminui a difusividade do solvente no $\mathrm{CO}_{2}$ supercrítico com consequente influência nos fenômenos de transferência de massa, diferentes solventes apresentam comportamentos diversos frente a mudanças nas condições experimentais 
[30]. Além disso, a acetona apresenta menor viscosidade e tensão superficial que o DMSO. Estas características influenciam a dinâmica da interação da solução orgânica com o fluido supercrítico. Quando a fase orgânica é injetada no vaso de expansão junto ao $\mathrm{CO}_{2}$, existe, momentaneamente, uma interface entre o líquido e o fluido supercrítico. Acima do ponto crítico da mistura, em soluções contendo acetona como solvente, a interface tende a desaparecer mais rapidamente, quando comparada com o tempo de desaparecimento da interface de soluções onde DMSO é utilizado [23]. O tamanho e a morfologia das partículas são regidos pelo tempo de desaparecimento da interface das fases e o tempo de quebra do jato. A quebra do jato, fenômeno no qual a solução líquida injetada se desestabiliza e é arrastada pelo anti-solvente, é influenciada pela pressão, mas também por características do solvente empregado [25].

O dimetilsulfóxido é frequentemente usado por atender requisitos necessários para um solvente adequado, como versatilidade e por não interagir fortemente com as substâncias bioativas (soluto). Além disso, apresenta baixa toxicidade [29]. No caso de produção de partículas de polímeros, muitas vezes o diclorometano é utilizado.

\subsection{Temperatura}

A temperatura também é um parâmetro operacional que influencia as características das partículas micronizadas por SAS. Em geral, o aumento da temperatura é responsável pelo aumento do tamanho e distribuição de tamanho das partículas devido à menor capacidade de remoção de solvente pelo fluido supercrítico.

Micropartículas de acetato de gadolínio foram obtidas por SAS e o aumento da temperatura, de 308 a $333 \mathrm{~K}$, foi responsável pelo aumento do diâmetro médio das partículas. Não há evidência de formação de nanopartículas [25]. O mesmo efeito da temperatura foi observado na micronização de partículas de sulfatiazol utilizando acetona como solvente. Porém, em maiores valores de temperatura, em vez de partículas separadas, foram produzidos agregados de partículas com maior distribuição de tamanho. 
A faixa estudada foi de 313 a $343 \mathrm{~K}$. Esta tendência pode ser explicada pelo fato de que o aumento da temperatura diminui a supersaturação do meio. Deste modo, a taxa de nucleação é diminuída e, como consequência, partículas de maior tamanho são produzidas, sendo isto válido apenas para altos valores de pressão da câmara de expansão [30]. O aumento da temperatura também pode ser responsável pela formação de filmes, como observado na micronização de aztreonam [28]. O aumento do tamanho de partícula também foi observada por Zhao et al. [29] na formação de partículas de camptotecina. No entanto, embora a faixa analisada seja de 308 a 341 K, a influência deste parâmetro é mais evidente entre 319 e $341 \mathrm{~K}$.

Ao contrário da tendência observada até agora, alguns autores relatam a diminuição do tamanho da partícula, assim como distribuição de tamanho com o aumento da temperatura. O tamanho das partículas de extrato de Ginkgo biloba micronizadas por SAS diminui com o aumento da temperatura, sendo a diminuição mais acentuada entre 308 e 338 K. Acima disto, até 353 $\mathrm{K}$, a temperatura pouco influenciou o tamanho de partícula. A temperatura ótima encontrada foi de $338 \mathrm{~K}$. Uma das razões para esta diferença de comportamento pode ser atribuída ao solvente orgânico usado. Enquanto os autores supracitados tenham usado DMSO como solvente, na micronização de extrato de Ginkgo biloba foi utilizado etanol [26].

$\mathrm{Zu}$ et al. [27], no entanto, observaram diferentes efeitos na produção de vitexina dentro da faixa de temperatura estudada. Na primeira parte da faixa de temperatura, entre 313 e $323 \mathrm{~K}$, houve a diminuição do tamanho de partícula com o aumento da temperatura. Este efeito é acentuado. Já entre 323 e $343 \mathrm{~K}$, ocorre um ligeiro aumento do tamanho das partículas. A temperatura ótima encontrada pelos autores foi de $323 \mathrm{~K}$.

\subsection{Concentração da solução orgânica}

A concentração da substância bioativa no solvente orgânico também influencia a formação de partículas e suas características. Os estudos sugerem que o aumento da concentração do soluto no solvente orgânico aumenta o tamanho e distribuição de tamanho das partículas. O aumento 
da concentração aumenta a viscosidade da solução orgânica. Deste modo, há um aumento das forças coesivas entre os componentes do jato que, por sua vez, retarda a sua quebra [25]. Além disso, o aumento da concentração faz com que a supersaturação necessária para dar início ao processo de nucleação ocorra próximo da saída do capilar. Uma vez que o início da nucleação ocorre rapidamente, o tempo de crescimento das partículas aumenta, dando origem a partículas de maior tamanho e maior distribuição de tamanho. Por outro lado, em baixas concentrações, a nucleação se inicia em uma mistura de única fase. Assim, o tempo de crescimento das partículas diminui, diminuindo as taxas de transferência de massa com consequente diminuição do diâmetro médio das partículas, como observado na produção de partículas de paracetamol utilizando etanol como solvente. Neste caso as partículas tiveram seu tamanho aumentado de 2 para 4 um com o aumento da concentração de paracetamol na solução orgânica de 1 para 4\%, à $313 \mathrm{~K}$ e pressão de injeção de 200 bar [31].

O aumento da concentração de 10 a $150 \mathrm{mg} \cdot \mathrm{mL}^{-1}$ da solução de acetato de ítrio em DMSO promoveu o aumento de tamanho das partículas da escala nano para a escala micro. Os autores observaram que concentração da solução orgânica pode ou não afetar o tempo de desaparecimento da interface líquido-fluido. Em concentrações mais baixas a duração da interface não é sensível à presença do soluto. No entanto, em maiores valores de concentração, o tempo de duração da interface aumenta com o aumento da concentração. Nas pressões estudadas, 120 e 160 bar, o aumento da concentração promove o aumento do tamanho das partículas [32].

De Marco e Reverchon [25] verificaram a influência da concentração de acetato de gadolínio em DMSO entre 20 e 300 mg.mL ${ }^{-1}$. Em concentrações mais baixas, entre 20 e $90 \mathrm{mg} \cdot \mathrm{mL}^{-1}$, foram obtidas partículas entre 86 e $90 \mathrm{~nm}$, ao passo que em maiores valores de concentração, as partículas apresentaram tamanho micrométrico. A pressão se manteve fixa em 150 bar. A mesma tendência foi descrita na micronização de camptotecina, ainda que a faixa de concentração estudada tenha sido bastante inferior a utilizada por De Marco e Reverchon [25]. Houve um aumento do tamanho da partícula com o aumento da concentração de 1,25 a $3,75 \mathrm{mg} \cdot \mathrm{mL}^{-1}$, com posterior estabilização do tamanho até concentração de $5 \mathrm{mg} \cdot \mathrm{mL}^{-1}$ [26]. 
Na micronização de vitexina, a concentração foi uma dos fatores considerados significativos no tamanho das partículas. $O$ aumento da concentração de soluto na fase orgânica foi responsável por efeitos antagônicos nas características das partículas. Em concentrações de 1,0 a 2,0 mg. $\mathrm{mL}^{-1} \mathrm{o}$ tamanho das partículas diminuiu drasticamente, ao passo que na faixa de concentração de 2,0 a $2,5 \mathrm{mg} \cdot \mathrm{mL}^{-1} \mathrm{o}$ tamanho das partículas aumentou. A variação de outros parâmetros operacionais pode ter influenciado a não concordância do efeito da concentração no tamanho das partículas [27]. Na produção de partículas de extrato de Ginkgo biloba a variação da concentração não causou nenhum efeito no tamanho das partículas dentro da faixa de concentração estudada, que ficou compreendida entre 1,25 a 3,75 mg.mL ${ }^{-1}$ [26].

\subsection{Vazão da solução orgânica}

A influência da vazão da solução contendo a droga também foi estudada por diversos autores. $\mathrm{Zu}$ et al. [27] não verificou nenhuma tendência no diâmetro médio de partícula com o aumento da vazão, corroborando os dados obtidos por Zhao et al. [29] que não observou nenhuma relação entre variação de vazão e tamanho das partículas, sendo que as faixas de vazão estudadas foram bastante próximas. Na micronização de extrato de Ginkgo biloba houve diminuição do tamanho da partícula com aumento da vazão de 3 para $6 \mathrm{~mL} \cdot \mathrm{min}^{-1}$. No entanto, efeito contrário foi observado em vazões superiores a $9 \mathrm{~mL} \cdot \mathrm{min}^{-1}$.

Para partículas de axetil cefuroxima precipitadas com polivinilpirrolidona, o aumento da vazão da solução aumenta a distribuição de tamanho das partículas. Segundo os autores, isso pode ser explicado pelo fato de que a vazão interfere no regime de quebra do jato e cinética de nucleação. Maior vazão implica em maior possibilidade de quebra, além de aumentar o volume de solvente por transferência de massa, sendo mais difícil removê-lo. Se ocorre menor remoção do solvente, a supersaturação diminui, aumentando o tamanho da partícula. Além disso, maior vazão aumenta a probabilidade de colisão entre as partículas, com tendência 
a aglomeração [2]. Por outro lado, Careno et al. [30] observou que o aumento da velocidade do jato diminui o diâmetro médio das partículas e sua distribuição de tamanho. Isso porque o aumento da velocidade promove uma mistura mais efetiva entre as fases, promovendo maior transferência de massa e maior frequência de nucleação. Com o aumento da vazão da solução aumenta-se a concentração de solvente na câmara de expansão, favorecendo a fusão das partículas formadas. O efeito do aumento da vazão da solução sobre o diâmetro das partículas depende do valor da vazão de $\mathrm{CO}_{2}$ utilizada. Se a razão entre as vazões for mantida constante, provavelmente irá ocorrer a diminuição do diâmetro das partículas formadas. Caso o aumento da vazão da solução orgânica ocorra mantendo-se a vazão de $\mathrm{CO}_{2}$ constante, a concentração de solvente orgânico aumenta na câmara de precipitação, o que pode levar a uma maior tendência de aglomeração das partículas formadas.

\subsubsection{Morfologia}

As partículas produzidas por esta técnica apresentam diferentes morfologias dependendo das condições operacionais do processo. Como ocorre na técnica RESS, há uma diminuição da cristalinidade das partículas durante o processamento $[24,27,29,33,34]$. As partículas obtidas podem apresentar formato esférico, como ocorre com partículas de Ginkgo biloba [26], partículas de vitexina [27] e camptotecina micronizadas em condições supercríticas do diagrama de fases [29]. Enquanto Careno et al. [30] não observaram influência da temperatura da câmara de expansão na morfologia das partículas, Chang et al. [28] verificaram que o aumento da temperatura de 318,2 para 328,2 K modifica a transformação de partículas esféricas em filmes com pequena quantidade de partículas dispersas sobre o mesmo. Para a mesma droga, aztreonam, o aumento da pressão para acima da pressão crítica da mistura promove a formação de partículas com formato esférico definido. Em condições subcríticas, houve formação de placas da droga camptotecina com tendência à aglomeração, como também observado por $\mathrm{Zu}$ et al. [27, 29]. Partículas de acetaminofeno pro- 
cessadas por SAS apresentaram formato regular e tamanho de partículas homogêneo, quando produzidas em pressão de 110 bar e temperatura de 308 K [34]. Nos testes in vitro realizados, a taxa de dissolução da droga micronizada aumenta significativamente quando comparada com a droga não processada.

A técnica SAS também tem sido utilizada para a complexação de substâncias bioativas com ciclodextrinas, polímeros e lipossomas a fim de mascarar sabores não palatáveis, aumentar a biodisponibilidade de fármacos, direcionar a droga ao seu alvo no organismo, diminuindo a dose diária ingerida, entre outras aplicações [35].

As variáveis operacionais da técnica SAS interferem não apenas no tamanho das partículas geradas, mas também na carga da droga na matriz e eficiência de encapsulamento, complexação ou co-precipitação [37].

Além disso, $\mathrm{CO}_{2}$ supercrítico como anti-solvente dilui a solução orgânica, diminuindo a fração molar do soluto. Com isto, ocorre uma diminuição do potencial químico, o que induz uma transição de fase, aumentando a eficiência de encapsulamento [36].

\subsubsection{Sistemas encapsulados/complexados}

Lipossomas apresentam grande potencial de uso na indústria farmacêutica e também podem ser produzidos utilizando a técnica SAS. No entanto, ainda há poucos estudos de encapsulamento de drogas em lipossomas que utilizam tecnologias supercríticas.

Lesoin et al. [38] estudou a formação de micropartículas de lecitina de soja, uma fonte recorrente de fosfolipídio por seu baixo custo, utilizando a técnica SAS, com posterior hidratação para formação dos lipossomas. A influência da variação da pressão formação de partículas de lecitina foi estudada na faixa de 90 a 130 bar. Todos os experimentos ocorreram à temperatura de $308 \mathrm{~K}$ e vazão $22,8 \mathrm{~mL} \cdot \mathrm{h}^{-1}$ e foram utilizados $2 \mathrm{~g}$ de lecitina. Os autores observaram que as partículas se agregam em valores mais baixos de pressão. O tamanho das partículas de lecitina em etanol, assim como a morfologia das mesmas não foram influenciadas pela variação 
de pressão, o que contradiz a maioria dos estudos que aponta uma diminuição do tamanho da partícula com o aumento da pressão. Já para a formação do lipossoma com calceína como substância a ser encapsulada, o aumento da pressão de precipitação diminui a população de lipossomas de menor tamanho, sendo obtidas duas faixas: de 0,1 a $1 \mu \mathrm{m}$ e 8 a 500 $\mu \mathrm{m}$. A população de lipossomas de tamanho médio, entre 1 e $10 \mu \mathrm{m}$ não foi afetada pela variação da pressão, uma vez que a alta velocidade de agitação promove a homogeneidade da mistura de fosfolipídios e água. As partículas apresentaram morfologia esférica.

A razão molar de $\mathrm{CO}_{2}$ /etanol foi analisada e observou-se que este parâmetro não exerceu influência no tamanho da lecitina processada. No entanto, em valores mais baixos (razão de 50), não houve uma micronização eficiente. Já o aumento da razão molar $\mathrm{CO}_{2} /$ etanol causou um efeito positivo no tamanho das partículas dos lipossomas [20].

Embora na micronização da lecitina pura o incremento da concentração na solução orgânica tenha aumentado o tamanho da partícula, o mesmo efeito não foi observado para os lipossomas, cujo tamanho se mostrou independente de variações de concentração. $O$ aumento do tamanho da partícula pode ser explicado pelo fenômeno conhecido como "Ostwald ripening", onde as partículas se agregam a fim de minimizar interações não favoráveis energeticamente [20]. O mesmo fenômeno pode ser observado na formação de lipossomas por meio de microemulsões em meio supercrítico quando há variação dos parâmetros experimentais. Assim, a influência da taxa de despressurização na formação de lipossomas pode ser explicada pela variação das características físicas do meio operacional. Na etapa de despressurização o fosfolipídio sofre uma transição de fase (fluida para gel). As interações entre as caudas do surfactante induz a formação da bicamada lipídica e conferem estabilidade ao lipossoma. De modo geral, maiores taxas de despressurização tendem à formação de lipossomas de tamanho menor. A temperatura também afeta a estrutura dos lipossomas formados. Baixas temperaturas favorecem a fase lamelar gel, de modo que as caudas hidrofóbicas estejam mais unidas e a bicamada mais compacta. Temperaturas mais altas favorecem a fase fluida cristalina, que também é favorecida a altas pressões, onde as caudas estão mais separadas, o que representa uma vanta- 
gem, uma vez que se pode utilizar temperaturas mais amenas na produção de partículas de substância termolábeis [38].

Matrizes poliméricas têm sido bastante utilizadas como suporte para fármacos. Estes arranjos são importantes na aplicação de sistemas de liberação controlada de substâncias bioativas. Desta forma, a droga encapsulada pode ser liberada por difusão, através da membrana porosa ou polimérica ou por degradação da estrutura do polímero. Podem ocorrer também mudanças nas propriedades de difusão das moléculas da matriz devido ao inchaço do polímero por entrada do solvente $\mathrm{O}$ uso de $\mathrm{CO}_{2}$ supercrítico apresenta a vantagem de mimetizar o aquecimento no meio operacional, de modo que a incorporação de drogas sensíveis termicamente seja possível [1]. Tendência semelhante à observada na formação de lipossomas foi notada na co-precipitação de partículas de axetil cefuroxima com o polímero polivinilpirrolidona (PVP) utilizando metanol como solvente. A variação de pressão não influenciou significativamente o tamanho das partículas na faixa entre 100 e 150 bar. Entre 150 e 200 bar, o diâmetro médio das partículas de compósito aumenta de 2,72 para 3,97 $\mu \mathrm{m}$ (temperatura de $313 \mathrm{~K}$, concentração de $100 \mathrm{mg} \cdot \mathrm{L}^{-1}$ ) com o aumento da pressão, assim como aumenta também a distribuição de tamanho das mesmas, não corroborando os dados da literatura. Uma das explicações dadas pelos autores é que, uma vez que a pressão influencia o regime da quebra do jato, a mudança do mesmo pode causar discrepâncias nas tendências esperadas [2]. No encapsulamento de alecrim em polaxâmeros utilizando etanol como solvente foram obtidas partículas isoladas com tamanho menor que $1 \mu \mathrm{m}$. A vazão de $\mathrm{CO}_{2}$ foi fixada em $0,7 \mathrm{~kg} \cdot \mathrm{h}^{-1}$ e a vazão da solução orgânica em $1 \mathrm{~mL} \cdot \mathrm{min}^{-1}$. No entanto, houve também formação de agregados maiores que $200 \mu \mathrm{m}$. O aumento da pressão para 140 bar, ao contrário do observado por Uzun et al. [2], diminui o tamanho dos aglomerados para valores entre 5 e $20 \mu \mathrm{m}$ [39]. Esta diminuição de tamanho pode ser devida ao efeito inibidor causado pelo polímero ao inibir o crescimento das partículas, bloqueando sua superfície e tornando-a menos vulnerável à agregação [2].

A eficiência de impregnação da droga na matriz polimérica também pode ser afetada por parâmetros operacionais, uma vez que o preen- 
chimento do polímero com a substância bioativa pode enfraquecer as interações químicas entre o polímero e a droga [40].

A técnica SAS também tem sido utilizada para a complexação de substâncias bioativas com ciclodextrinas. As ciclodextrinas são oligossacarídeos cíclicos hidrossolúveis devido à presença de grupos hidroxilas na parte externa de seu anel. A cavidade interna das ciclodextrinas apresenta caráter hidrofóbico e, por este motivo, pode abrigar moléculas. As ciclodextrinas (CD) naturais se diferenciam pelo número de grupos glicopiranose que formam sua estrutura troncocônica. A $\alpha$-ciclodextrina, a $\beta$-ciclodextrina e a $\gamma$-ciclodextrina apresentam 6, 7 e 8 grupos glicopiranose em sua estrutura, respectivamente. A $\alpha$-CD se mostra insuficiente para a complexação de várias drogas e a $\gamma$-CD apresenta um custo muito elevado, dificultando sua utilização na síntese farmacológica. A $\beta$-CD possui uma cavidade interna que consegue alocar uma grande variedade de drogas e apresenta grande disponibilidade [35]. Possui ampla aplicação em várias áreas, como alimentícia e agrícola. Na área farmacêutica é utilizada para aumentar a solubilidade de fármacos em meio aquoso, melhorando, consequentemente, a biodisponibilidade de drogas [25]. Além disso, podem formar complexos de inclusão que aumentam a estabilidade de ingredientes ativos e melhoram características organolépticas de medicamentos [41].

Há vários métodos para complexação de drogas/ciclodextrinas em solução, tais como métodos spray drying, evaporação e métodos de precipitação. No entanto, estes métodos apresentam a desvantagem de apresentarem processos em várias etapas e operações em altas temperaturas, além da baixa eficiência. Com frequência o complexo originado por meio destes métodos apresenta grande quantidade de solvente residual. Tecnologias supercríticas tem se mostrado importantes na complexação de fármacos sensíveis termicamente com ciclodextrinas [24, 41].

Partículas esféricas de dicloridrato de cetirizina complexado com 囚-ciclodextrina foram obtidas por meio da técnica SAS, utilizando dimetilsulfóxido como solvente. Embora as partículas tenham apresentado morfologia homogênea, foi possível notar algumas estruturas aglomeradas. As partículas precessadas apresentaram pequena distribuição de tamanho $(2,12$ a 4,16 $\mu \mathrm{m})$ devido à rápida transferência de massa entre 
o solvente e o fluido supercrítico. Já a complexação de sinvastatina com hidroxipropil- $\beta$-ciclodextrina originou partículas amorfas, com redução drástica da cristalinidade. A técnica SAS mostrou ser vantajosa quando comparada com o processo envolvendo a mistura física da droga e $\beta$-ciclodextrina, uma vez que, em meio supercrítico, é possível complexar a droga no interior da cavidade hidrofóbica. A complexação, nas condições de pressão igual a 150 e temperatura igual a 308,15 K, foi analisada por ressonância nuclear de hidrogênio $\left(\mathrm{RMN}-\mathrm{H}^{1}\right)$. Assim, a cetirizina não

atinge os receptores orais de sabor, tornando a ingestão do fármaco mais palatável que a droga complexada mistura física ou por freeze-drying. Foi analisada a quantidade solvente residual no fármaco, indicando que a técnica pode contribuir de maneira eficiente para sua eliminação, uma vez que valores bem abaixo do permitido pela legislação foram encontrados. Embora o processo SAS tenha influenciado nas características das partículas de maneira distinta de outras técnicas, não há diferença no perfil de dissolução do complexo em testes in vitro [35].

Embora a complexação não afete a estrutura da sinvastatina, verifica-se alteração em sua morfologia quando complexada com hidroxipropil- $\beta$-ciclodextrina por SAS. As análises por difração de raio-X indicam redução da cristalinidade das partículas, com transição para o estado amorfo. A taxa de dissolução da droga, intimamente relacionada com sua biodisponibilidade, aumentou, segundo o resultado dos testes in vitro, devido à possível formação de ligação de hidrogênio entre a droga e a cavidade da ciclodextrina [42]. Uma alternativa para a complexação de ciclodextrinas com drogas hidrofóbicas é a utilização de agentes auxiliares, uma vez que eles podem aumentar a eficiência de inclusão do fármaco na matriz utilizada [41].

\subsubsection{Partículas a partir de Soluções Gasosas Saturadas (PGSS)}

Esta técnica (Figura 10.3) se baseia na capacidade do $\mathrm{CO}_{2}$ supercrítico em se dissolver no soluto de interesse à alta pressão com posterior expansão por meio da passagem da mistura por um orifício até o vaso 
de expansão. Como consequência, ocorre a precipitação do soluto, uma vez que o gás é removido com o abaixamento da pressão [43].

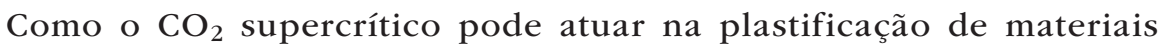
utilizados para encapsular substâncias bioativas, tais como polímeros, a técnica PGSS também se mostra adequada para a formação de compósitos de sistemas de liberação controlada de fármacos [44]. Além disso, apresenta a vantagem de dispensar o uso de co-solventes [1].

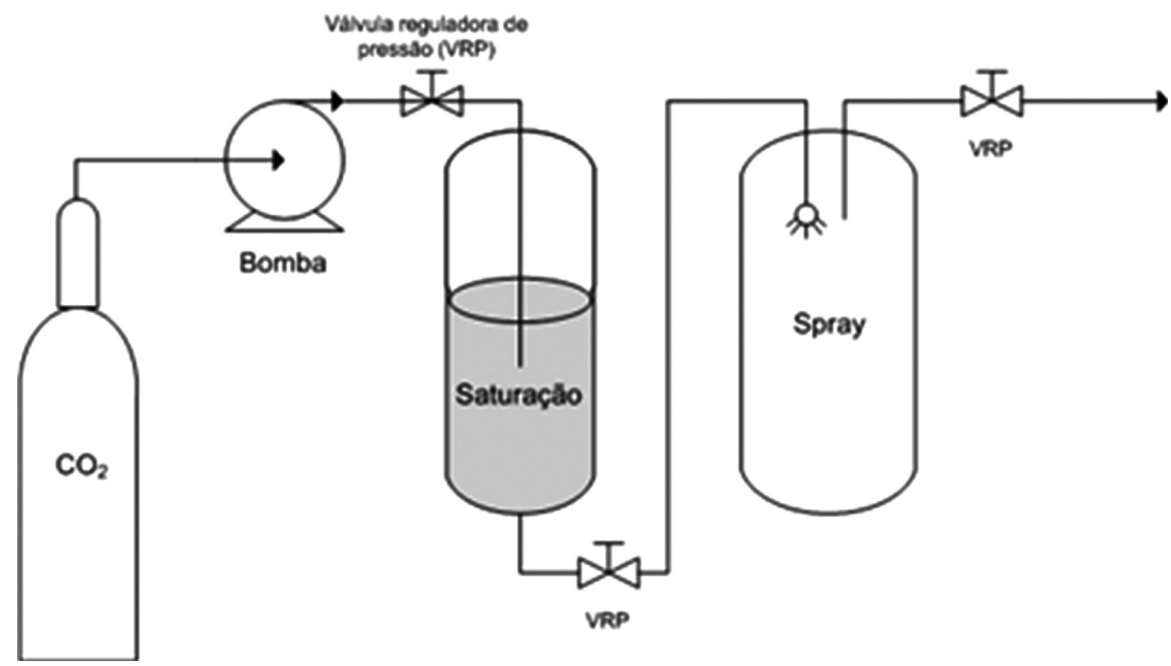

Figura 10.3. Desenho esquemático do sistema de formação de partículas pela técnica PGSS.

Durante a expansão, na técnica PGSS, assim como na RESS e SAS, ocorre o resfriamento da mistura por efeito Joule-Thompson, de modo a promover a solidificação do soluto de interesse. Como baixas temperaturas de pré-expansão favorecem este efeito, espera-se que partículas de menor diâmetro médio sejam formadas nestas condições. Esta tendência é corroborada por Yun et al. [45] que estudaram a produção de partículas de lecitina encapsuladas em polietilenoglicol (PEG), um polímero hidrofílico, por meio de PGSS. Foram obtidas partículas com diâmetro médio de 1,13 $\mu \mathrm{m}$, analisadas por microscopia eletrônica de varredura (MEV). O aumento da temperatura de 313 para $323 \mathrm{~K}$ promoveu um aumento do tamanho das partículas. 
O mesmo efeito foi verificado na produção de partículas de óleo essencial de lavandina encapsulado também em PEG. As partículas também foram analisadas por MEV. O aumento da temperatura promoveu o aumento do tamanho das partículas, assim como se pode verificar a existência de alguns aglomerados. As partículas processadas apresentaram morfologia esférica e com pequena distribuição de tamanho [40].

Efeito semelhante pode ser verificado em técnicas modificadas. Partículas de $\beta$-caroteno encapsuladas em lecitina de soja foram obtidas por PGSS-drying, no qual o soluto está disperso em meio aquoso e o fluido supercrítico atua como secante. $\mathrm{O}$ aumento da temperatura de pré-expansão causou um aumento do tamanho das partículas, sendo esta tendência mais evidente na condição de pressão de 90 bar e menos evidente a pressão de 100 bar [46].

A mesma substância bioativa, $\beta$-caroteno, encapsulada poli-( $\varepsilon$-prolactona) (PCL) apresentou comportamento oposto diante da variação do mesmo parâmetro operacional, uma vez que o aumento da temperatura de 323 a $343 \mathrm{~K}$ foi responsável pela diminuição do tamanho das partículas, embora esta influência tenha sido pouco consistente. As partículas em cápsulas poliméricas alcançaram tamanho entre 110 e $130 \mu \mathrm{m}$ [47]. A mesma tendência foi observada na micronização de partículas de polietilenoglicol (PEG) utilizando PGSS-drying. O aumento da temperatura de pré-expansão de 353 para $414 \mathrm{~K}$ causou a diminuição do tamanho das partículas, que apresentaram morfologia esférica e tamanho médio menor que $10 \mu \mathrm{m}$. Uma das razões para o observado, segundo os autores, é que a remoção da água ocorre de forma mais eficiente em temperaturas mais altas [43] .

A pressão é outro parâmetro operacional que influencia o tamanho e morfologia das partículas produzidas pela técnica PGSS. Maiores valores de pressão intensificam o efeito Joule-Thompson, de modo que a atomização se torna mais eficiente, gerando partículas de menor tamanho. Além disso, maiores valores de pressão aumentam a concentração de $\mathrm{CO}_{2}$ solubilizado no polímero, diminuindo a viscosidade da solução [40, 43].

O aumento da pressão na pré-expansão de 65 a 151 bar originou partículas de PEG de menores tamanhos obtidas por PGSS-drying. Isso porque ocorre um aumento da concentração de $\mathrm{CO}_{2}$ dissolvido na solução 
e este, por sua vez, intensifica o efeito Joule-Thompson, dando origem a partículas de menor tamanho [40,43]. Os autores observaram o mesmo efeito da pressão, na faixa de 50 a 90 bar, no compósito de óleo essencial de lavandina em PEG. O aumento da pressão de 200 a 300 bar levou à diminuição do diâmetro médio de partículas de lecitina encapsulada [45].

Efeito contrário foi observado na produção de $\beta$-caroteno encapsulado em PCL [47]. Uma das razões para o observado advém do fato de que maiores partículas são produzidas em maiores razões molares de $\beta$-caroteno encapsulado/PCL. Como a quantidade de $\beta$-caroteno em PCL é sensível à variação de pressão, o aumento desta variável faz com que a concentração de $\beta$-caroteno seja maior, dando origem a partículas de maior tamanho.

A razão entre a solução e $\mathrm{CO}_{2}$ e a razão entre droga e aditivo influenciou o tamanho da partícula. Para $\beta$-caroteno em polímero ocorre o aumento do tamanho das partículas até um platô com o aumento da razão droga/ polímero. A impregnação também aumenta com o aumento da razão [47]. Martín et al. [43], por outro lado observou uma diminuição do tamanho da partícula com o aumento da razão $\mathrm{CO}_{2} /$ solução. O aumento da concentração de $\mathrm{CO}_{2}$ na solução saturada torna a atomização mais efetiva, estimulando a produção de partículas menores.

Os parâmetros operacionais também influenciam a carga da droga na matriz carreadora. A concentração de $\beta$-caroteno em PCL aumenta com o aumento da temperatura e pressão, como já citado [47]. O aumento da temperatura aumenta a eficiência da impregnação de óleo essencial de lavandina em PEG. Já o aumento da pressão diminui a eficiência de encapsulamento, uma vez que solubilidade do óleo essencial no fluido supercrítico tende a aumentar, diminuindo a interação entre óleo e polímero [40].

As partículas produzidas por PGSS apresentaram morfologia esférica [43, 48]. Partículas de polibutileno tereftalato (PBT) foram micronizadas, sendo que as temperaturas pré e pós-expansão foram os parâmetros operacionais de maior influência no formato das partículas. As diferentes condições de jato também influenciaram as características do polímero processado [49]. Partículas pequenas de $\beta$-caroteno encapsuladas e com tamanho regular foram obtidas com polímeros de menor massa molar. 
Os autores acreditam que isso se deve a maior solubilidade de $\mathrm{CO}_{2} \mathrm{em}$ polímeros de menor massa molar [47].

\subsubsection{Outras técnicas}

Micropartículas de poli(ácido L-láctico) foram produzidas pela técnica de Aumento da Dispersão da Solução por Fluido Supercrítico (SEDS) modificada como sistema de liberação controlada de morfina. Na técnica SEDS, a solução orgânica e o fluido supercrítico, que atua como anti-solvente, são injetados no vaso de expansão por diferentes capilares concomitanetemente. Partículas do complexo atingiram diâmetro médio de 2,45 $\mathrm{mm}$, observadas por MEV, com morfologia de esferóides. Neste estudo foi usado um orifício triaxial. Ao $\mathrm{CO}_{2}$ supercrítico foi adicionado etanol e a solução orgânica foi composta de diclorometano como solvente. A eficiência de impregnação foi pequena pela solubilidade da droga em etanol, que arrastou a morfina [50].

Baldyga et al. [51] estudaram a micronização de partículas de nicotina e diclofenaco e observaram pela mesma técnica e observaram que o tamanho das partículas é intimamente relacionado com a o tamanho das gotículas e pode auxiliar na previsão de regiões onde se formam agregados.

Apesar deste método, em geral, produzir partículas com menores diâmetros [1], a mistura entre a solução orgânica e o anti-solvente ocorre no interior do atomizador que pode levar a precipitação no seu interior com possíveis interrupções do processo.

A técnica Anti-Solvente Gasoso (GAS) foi utilizada na produção de partículas de alecrim encapsulado em policaprolactona. Esta técnica se baseia na introdução de um gás pressurizado em uma solução líquida composta da droga e de um solvente orgânico. Com a introdução de $\mathrm{CO}_{2}$ no precipitador, há uma diminuição do poder de solvatação do líquido, causando precipitação do sólido [1]. Neste estudo, diclorometano foi

utilizado como solvente. A razão droga/polímero foi de 1:2. A técnica foi responsável por partículas de menor distribuição de tamanho quando comparadas com a produção de partículas pelo método de evaporação. 
As partículas atingiram tamanhos menores que $254,5 \mu \mathrm{m}$, sendo que o aumento da pressão favorece a diminuição do tamanho das partículas. A eficiência de encapsulamento também se mostrou mais eficiente que pelo método tradicional. Ensaios de liberação in vitro mostram comportamento semelhante à morfina encapsulada por SEDS, sugerindo que a alta taxa de liberação inicial seja em decorrência de partículas da droga localizadas na superfície do polímero [36].

\subsection{Conclusão}

Há várias técnicas para produção de nano e micropartículas. As condições operacionais dos diversos processos influenciam as características das partículas, tais como tamanho e distribuição de tamanho e morfologia. Estas características, por sua vez, são responsáveis pelo comportamento da droga no organismo, de modo que é possível modificar parâmetros de operação a fim de atender alguma necessidade fisiológica específica.

Em todas as técnicas citadas, é recorrente o uso de $\mathrm{CO}_{2}$ como fluido supercrítico. Dependendo do processo, $\mathrm{O} \mathrm{CO}_{2}$ pode atuar como solvente, anti-solvente ou soluto. As técnicas podem ser usadas na micronização, complexação, encapsulamento, entre outros, e apresentam várias vantagens, como diminuição do uso de solventes orgânicos, diminuição de solvente residual no produto final. Mudanças nas propriedades físico-químicas do fluido supercrítico podem ser obtidas com a variação das condições operacionais e os processos podem ocorrer em condições brandas de temperatura e pressão, sendo adequadas para a produção de partículas de drogas termolábeis.

A possibilidade da co-precipitação de substâncias diferentes também é uma das vantagens das tecnologias supercríticas, que se mostraram adequadas para sintetizar partículas de substâncias bioativas em lipossomas, polímeros, ciclodextrinas a fim de mascarar sabor de fármacos, direcionar drogas a uma região específica do corpo, proteção de substâncias com ação biopesticida, proteger compostos da indústria cosmética, entre outros. 
As tecnologias supercríticas se mostraram adequadas para a micronização de partículas e formação de complexos ou materiais encapsulados, gerando partículas pequenas e com pequena distribuição de tamanho. Espera-se que o desenvolvimento de aparatos instrumentais aplicados às técnicas supercríticas torne a produção de partículas alvo de estudo tanto em escala laboratorial como em escala industrial, tornando o processo economicamente viável e com ampla aplicação.

\subsection{Referências}

[1] P. York, U.B. Kompella, B.Y. Shekunov. Supercritical Fluid Technology for Drug Product Development, Marcel Dekker: Nova York, 2004.

[2] I.N. Uzun, O. Sipahigil, S. Dinçer, J. Supercrit. Fluids 2011, 55, 1059-1069.

[3] S. Yeo, S. Kiran, J. Supercrit. Fluids 2011, 34, 287-308.

[4] D.A. Chiappetta, C. Hocht, C. Taira, A. Sosnik, Biomaterials 2011, 32, 2379-2387.

[5] M.S. da Silva, R. Viveiros, P.I. Morgado, A. Aguiar-Ricardo, I.J. Correia, T. Casimiro, Int. J. Pharm. 2011, 416, 61-68.

[6] M. Vijayaraghavan, S. Stolnik, S.M. Howdle, L. Illum, Int. J. Pharm. 2012, 438, 225-231.

[7] K. Mishima, Adv. Drug Deliv. Rev. 2008, 60, 411-432.

[8] M. Türk, D. Bolten, J. Supercrit. Fluids 2010, 55, 778-785.

[9] M. Pourasghar, S. Fatemi, A. Vatanara, A.R. Najafabadi, Powder Technol. 2012, 225, 21-26.

[10] H.R. Satvati, M.N. Lotfollahi, Powder Technol. 2011, 210, 109-114.

[11] A. Keshavarz, J. Karimi-Sabet, A. Fattahi, A. Golzary, M. Rafiee-Tehrani, F.A. Dorkoosh, J. Supercrit. Fluids 2012, 63, 169-179.

[12] C. Su, M. Tang, Y. Chen, J. Supercrit. Fluids 2009, 50, 69-76.

[13] A. Z. Hezave, S. Aftab, F. Esmaeilzadeh, J. Supercrit. Fluids 2010, 55, 326-324.

[14] Z. Huang, S. Kawi, Y.C. Chiew, J. Supercrit. Fluids 2004, 30, 25-39.

[15] C. Atila, N. Yildiz, A. Çalimli, J. Supercrit. Fluids 2010, 51, 404-411.

[16] A. Z. Hezave, F. Esmaeilzadeh, Adv. Powder Technol. 2011, 22, 587-595.

[17] M. Türk, J. Supercrit. Fluids 2009, 47, 537-545.

[18] C. Vemavarapu, M.J. Mollan, T.E. Needham, Powder Technol. 2009, 189, 444-453.

[19] N.C. Santos, M.A.R.B. Castanho, Química Nova 2002, 25, 1181-1185.

[20] L. Lesoin, O. Boutin, C. Crampon, E. Badens, Colloid Surface A 2011, 377, 1-14.

[21] Z. Wen, B. Liu, Z. Zheng, X. You, Y. Pu, Q. Li, Chem. Eng. Res. Des 2010, 88, 1102-1107.

[22] A. Sane, J. Limtrakul, J. Supercrit. Fluids 2009, 51, 230-237.

[23] E. Reverchon, E. Torino, S. Dowy, A. Braeuer, A. Leipertz, Chem. Eng. J. 2010, 156, 446-458. 
[24] M.Y. Lee, H.S. Ganapathy, K.T. Lim, J. Phys. Chem. Solids 2010, 71, 630-633.

[25] I. De Marco, E. Reverchon, J. Supercrit. Fluids 2011, 58, 295-302.

[26] C. Zhao, L. Wang, Y. Zu, C. Li, S. Liu, L. Yang, X. Zhao, B. Zu, Powder Technol. 2011, 209, 73-80.

[27] Y. Zu, Q. Zhang, X. Zhao, D. Wang, W. Li, X. Sui, Y. Zhang, S. Jiang, Q. Wang, C. Gu, Powder Technol. 2012, 228, 47-55.

[28] S. Chang, T. Hsu, Y. Chu, H. Lin, M. Lee, J. Taiwan Inst. Chem. Eng. 2012, 43, 790-797.

[29] X. Zhao, Y. Zu, Q. Li, M.Wang, B. Zu, X. Zhang, R. Jiang, C. Zu, J. Supercrit. Fluids 2010, 51, 412-419.

[30] S. Careno, O. Boutin, E. Badens, J. Crystal Growth 2012, 342, 34-41.

[31] S. Dowy, A. Braeuer, K. Reinhold-López, A. Leipertz, J. Supercrit. Fluids 2010, 55, 282-291.

[32] A. Braeuer, S. Dowy, E. Torino, M. Rossmann, S.K. Luther, E. Schluecker, A. Leipertz, E. Reverchon, Chem. Eng. J. 2011, 173, 258-266.

[33] M. Rossmann, A. Braeuer, S. Dowy, T. Gottfried Gallinger, A.Leipertz, E. Schluecker, J. Supercrit. Fluids 2012, 66, 350-358

[34] G.H. Chong, R. Yunus, T.S.Y. Choong, N. Abdullah, S.Y. Spotar, J. Supercrit. Fluids 2011, 60, 69-74.

[35] C. Lee, S. Kim, Y. Youn, E. Widjojokusumo, Y. Lee, J. Kim, Y. Lee, R.R. Tjandrawinata, J. Supercrit. Fluids 2010, 55, 348-357.

[36] O. Yesil-Celiktas, E.O. Cetin-Uyanikgi, J. Supercrit. Fluids 2012, 62, 219-225.

[37] A. Galia, O. Scialdone, G. Filardo, T. Spanò, Int. J. Pharm. 2009, 377, 60-69.

[38] L. Lesoin, O. Boutin, C. Crampon, E. Badens, Colloid Surface A 2011, 377, 1-14.

[39] A. Visentin, S. Rodríguez-Rojo, A. Navarrete, D. Maestri, M.J. Cocero, J. Food Eng. 2012, 109, 9-15.

[40] S. Varona, S. Rodríguez-Rojo, Á. Martín, M.J. Cocero, C.M.M. Duarte, J. Supercrit. Fluids 2011, 58, 313-319.

[41] M. Banchero, L. Mann, J. Supercrit. Fluids 2011, 57, 259-266.

[42] S.W. Jun, M. Kim, J. Kim, H.J. Park, S. Lee, J. Woo, S. Hwang, Eur. J. Pharm. Biopharm. 2007, 66, 413-421.

[43] Á. Martín, H.M. Pham, A. Kilzer, S. Kareth, E. Weidner, Chem. Eng. Process. 2010, 49, 1259-1266.

[44] M. Vijayaraghavan, S. Stolnik, S.M. Howdle, L. Illum, Chem. Eng. Process. 2012, 438, 225-231.

[45] J. Yun, H. Lee, A.K.M. Asaduzzaman, B.Chun, J. Ind. Eng. Chem. 2013, 19, 686-691.

[46] E. de Paz, Á. Martín, M.J. Cocero, J. Supercrit. Fluids 2012, 72, 125-133.

[47] E. de Paz, Á. Martín, C.M.M. Duarte, M.J. Cocero, Powder Technol. 2012, 217, 77-83.

[48] M. Pemsel, S. Schwab, A. Scheurer, D. Freitag, R. Schatz, E. Schlücker, J. Supercrit. Fluids 2010, 53, 174-178.

[49] S. Pollak, S. Kareth, A. Kilzer, M. Petermann, J. Supercrit. Fluids 2011, 56, 299-303.

[50] Y.Zhang, X. Liao, G. Yin, P.Yuan, Z. Huang, J. Gu, Y. Yao, X. Chen, Powder Technol. 2012, 221, 343-350.

[51] J. Bałdyga, D. Kubicki, B. Y. Shekunov, K. B. Smith, Chem. Eng. Res. Des. 2010, 88, 1131-1141. 